secuencia sería el origen de la duplicación uretral. La mayoría de los pacientes se diagnostican en los primeros años de vida ${ }^{4}$. La forma de presentación clínica más frecuente es la existencia de un doble meato uretral y/o un doble chorro miccional. Otras manifestaciones descritas son la presencia de infecciones urinarias de repetición, reflujo vesicoureteral, incontinencia y goteo perineal durante la micción ${ }^{5}$. El diagnóstico se basa en la exploración física completada con la cistouretrografía miccional seriada y la uretrocistoscopia ${ }^{6}$. La ecografía ayuda al diagnóstico de otras posibles anomalías urinarias asociadas. Las diferentes variantes anatómicas se agrupan según la clasificación de Effmann ${ }^{1}$ en 3 tipos, con diferentes subtipos, siendo la más frecuente el tipo iA que no tiene comunicación ni con la uretra ni con la vejiga.

El caso presentado correspondería con el tipo IIA1 de la clasificación de Effmann, con dos uretras no comunicadas entre sí que se originan de forma independiente en la vejiga. El tratamiento debe ser individualizado en función de la variante anatómica y de la repercusión clínico-funcional. Salle et $\mathrm{al}^{3}$ propusieron un esquema terapéutico orientador cuyas opciones van desde la abstención terapéutica hasta la exéresis de la uretra dorsal accesoria, pasando por la meatoplastia aislada, la uretroplastia con colgajo o la resección endoscópica del tabique interpuesto entre ambas uretras.

En conclusión, la duplicación uretral es una rara anomalía urológica de origen desconocido y cuya presentación clínica varía en función del tipo anatómico de la malformación. Su diagnóstico puede pasar desapercibido, especialmente en pacientes que presentan otras anomalías asociadas como hipospadias o extrofia vesical. El tratamiento debe ser individualizado y abarca desde la abstención terapéutica hasta diferentes opciones quirúrgicas dependiendo de la variante anatómica.

B I B L I O G R A F Í A

1. Effmann EL, Lebowitz RL, Colodny AH. Duplication of the urethra. Radiology. 1976;119:179-85.

2. Woodhouse CR, Williams DI. Duplications of the lower urinary tract in children. Br J Urol. 1979;51:481-7.

3. Salle JLP, Sibai H, Rosenstein D, Brzezinski AE, Corcos J. Urethral duplication in the male: Review of 16 cases. J Urol. 2000;163:1936-40.

4. Podesta ML, Medel R, Castera R, Ruarte AC. Urethral duplication in children: Surgical treatment and results. J Urol. 1998;160:1830-3.

5. Psihramis KE, Colodny AH, Lewobitz RL, Retik AB, Bauer SB. Complete patent duplication of the urethra. J Urol. 1986;136: 63-7.

6. Chaumoitre K. Voiding cystourethrography in boys. Does the presence of the catheter during voiding alter the evaluation of the urethra? J Urol. 2004;171:1280-1.

I. Fernández-Pineda*, M.A. Fernández-Hurtado,

R. Barrero Candau y F. García Merino

Sección de Urología Pediátrica, Servicio de Cirugía Pediátrica, Hospital Infantil Universitario Virgen del Rocío, Sevilla, España

*Autor para correspondencia.

Correo electrónico: israfdez@hotmail.com

(I. Fernández-Pineda).

\title{
Tumor testicular de células de Sertoli con marcadores neuroendocrinos positivos
}

\section{Sertoli cell tumor of the testis with positive neuroendocrine markers}

\section{Sr. Director:}

Los tumores de células de Sertoli (TCS) representan menos del $1 \%$ de todas las neoplasias testiculares y se engloban dentro del grupo de los tumores de los cordones sexuales junto con los tumores de células de Leidyg, los tumores de la granulosa y los mixtos.

Presentamos el caso de un paciente varón de 69 años, sin antecedentes de interés, que acudió a nuestra consulta por presentar algia testicular izquierda intermitente de varios meses de evolución, con ausencia de clínica miccional. El dolor se encontraba localizado a nivel del polo superior del testículo izquierdo, sin llegar a palpar irregularidades, masas o engrosamientos anormales. Se realizó una ecografía en la que encontramos una lesión intratesticular de $1,5 \mathrm{~cm} \times 1 \mathrm{~cm}$, hipoecogénica, homogénea, localizada a nivel del polo superior del testículo izquierdo y rodeada por una delgada cápsula, sin guardar relación con el epidídimo u otras estructuras testiculares (sospecha de quiste epidermoide). El resto del órgano era normal así como el contralateral. Los marcadores tumorales (AFP, B-hCG y LDH) fueron negativos. A la luz de los datos clinicoradiológicos se realizó una tumorectomía con biopsia intraoperatoria, informada como lesión de características benignas con pulpa adyacente totalmente normal, optando por cirugía conservadora. El análisis anatomopatológico definitivo fue de tumoración bien delimitada, no encapsulada, rodeada de tubos seminíferos con espermatogénesis completa. Presentaba patrón de crecimiento difuso constituida por nidos sólidos (fig. 1) con estructuras tubulares y retiformes, sin atipia citológica ni 


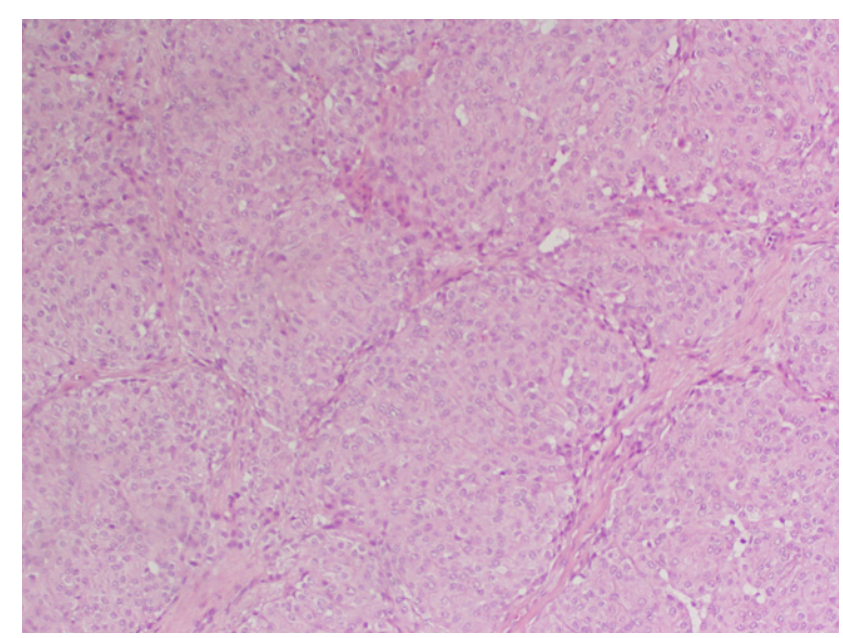

Figura 1 - Patrón de crecimiento difuso constituido por nidos sólidos con estructuras tubulares y retiformes.

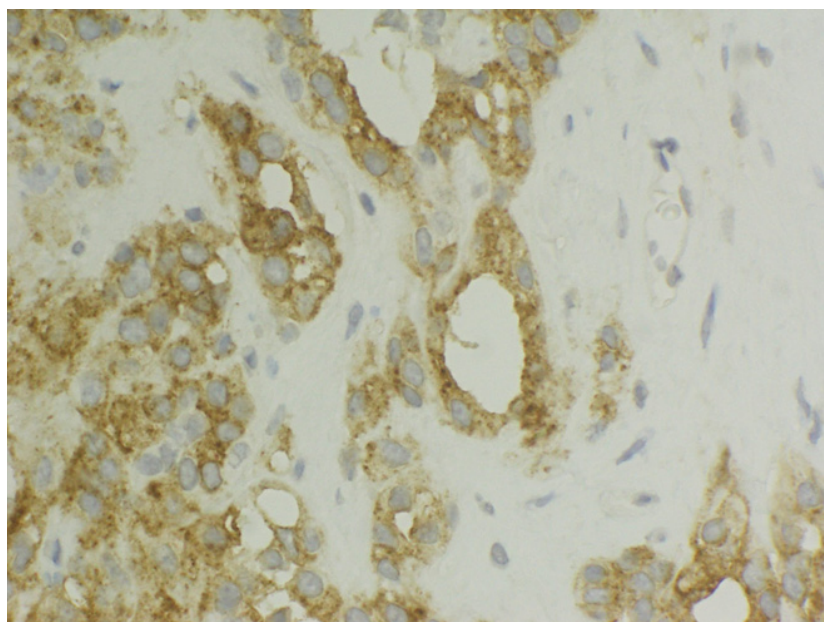

Figura 2 - Inmunorreactividad positiva para sinaptofisina.

mitosis. El estroma estaba marcadamente hialinizado y las células tumorales presentaban inmunorreactividad frente a vimentina, CD 99 y sinaptofisina (fig. 2), siendo débilmente positivas para inhibina. No expresaron PLAP, EMA, citoqueratina 7, CAM 5.2, CA 125, S-100, calretinina, actina, desmina, CD 117, HMB 45, PSA, ni Melan-A. Ultraestructuralmente, las células tumorales mostraron ausencia de gránulos de neurosecreción.

Con todos estos hallazgos, el diagnóstico definitivo fue de TCS variante clásica, sin rasgos que sugirieran malignidad y con la peculiaridad de la expresión de marcadores neuroendocrinos (sinaptofisina). Planteamos el diagnóstico diferencial con un tumor carcinoide (desechado por la morfología y por el estudio ultrastructural de esta lesión que no demostró la presencia de gránulos de neurosecreción) y con un tumor de células de Leydig (descartado por inmunihistoquímica).

El estudio se completó con una TAC abdominopélvica para descartar posibles adenopatías retroperitoneales, resultando completamente normal.
Actualmente y tras 12 meses de seguimiento, el paciente se encuentra asintomático, con marcadores, ECO testicular y exploración física rigurosamente normales.

Los TCS se engloban dentro de los tumores de los cordones sexuales junto con los tumores de células de Leidyg, los tumores de la granulosa y los tumores mixtos, considerándose una patología infrecuente pues tan solo representan el $1 \%$ de todos los casos diagnosticados. Pueden aparecer a cualquier edad, aunque la mayoría se encuentra entre los 15 y los 80 años, con una media de 45 años ${ }^{1}$.

Se suelen presentar de forma asintomática, con marcadores negativos y la mayor parte de las ocasiones como un hallazgo casual tras un estudio de imagen por otros motivos. No obstante y pese a que no son tan metabólicamente activos como los tumores de Leidyg, pueden ocasionar ginecomastia o precocidad sexual en relación con la producción excesiva de hormonas en aproximadamente un 20-30\% de los pacientes ${ }^{2}$. No se relacionan con la criptorquidia a diferencia de los tumores de células germinales, aunque sí se suele asociar en ocasiones a síndromes como el síndrome de Peutz Jeguers o el síndrome de Carney ${ }^{3}$. En nuestro caso se presentó en forma de dolor testicular en un varón de 69 años sin ningún signo o síntoma de sobreproducción hormonal y no asociado a otras patologías concomitantes.

Histopatológicamente podemos distinguir 3 subtipos: TCS clásico, TCS de células gigantes calcificadas y TCS esclerosante ${ }^{1,4}$.

La variante clásica es la más frecuente y posee un rango muy variable de características anatomopatológicas. Presenta un patrón tubular, con células de citoplasma amplio pálido o eosinófilo, núcleo vesiculoso con núcleo y estroma hialinizado. En casos complicados se realiza histoquímica con positividad para citoqueratina e inhibina y negatividad para PLAP.

El TCS de células gigantes calcificadas es otra variante con edad de presentación más precoz. Afecta fundamentalmente a niños y a varones en torno a los 20 años, con patrón de crecimiento sólido, células poligonales, prominente nucleolo y calcificaciones.

La variante esclerosante se considera extremadamente infrecuente, con 14 casos descritos en la literatura médica hasta la fecha ${ }^{5}$. Presenta pequeños tubos en un estroma escleroso. Suelen ser negativos o débilmente positivos para citoqueratina.

La gran mayoría de los TCS suelen ser de naturaleza benigna, no obstante, entre el $10-22 \%$ presentan capacidad de metastatización (menos de 50 casos publicados), guardando cierta relación con el subtipo tumoral ${ }^{6,7}$. Podríamos encontrar enfermedad metastásica en un 15-20\% de los del tipo células grandes calcificadas y entre un 5-10\% en el tipo clásico. No hay datos claros en cuanto a la capacidad de diseminación de los TCS esclerosos.

No existen en la actualidad criterios de malignidad unificados o estandarizados, aunque sí hay alteraciones histopatológicas que nos pueden orientar en gran medida, como son la moderada o severa atipia citológica, un diámetro mayor de $4-5 \mathrm{~cm}$, la presencia de más de 5 mitosis por cada 10 campos o la necrosis y la invasión vascular-linfática ${ }^{1,7}$. El único criterio inequívoco sigue siendo la presencia de metástasis (supervivencia media de 2 años en estos casos).

Existen casos descritos en la literatura médica ${ }^{8}$ de TCS con marcadores neuroendocrinos positivos, como en nuestro 
paciente, que dificultan el diagnóstico anatomopatológico y obligan a descartar, entre otras, la existencia de tumor carcinoide testicular. En el momento actual se desconocen las implicaciones clínicas de este hallazgo casual.

El tratamiento habitual de estas lesiones es la orquiectomía inguinal, acompañada de linfadenectomía retroperitoneal si se demuestran crecimientos ganglionares en los casos malignos ${ }^{9}$, así como poliquimioterapia sistémica y radioterapia (normalmente con pronóstico ominoso). Existen casos descritos en la literatura médica en los que se ha realizado cirugía conservadora (tumorectomías) en casos bilaterales, en varones prepuberales ${ }^{10}$ o en casos claramente benignos como en el nuestro. Es necesario un seguimiento a largo plazo debido a que se han descrito metástasis incluso a los 15 años desde el tratamiento. Debido a lo inusual de esta patología no existe una pauta para seguir, aunque sí se recomienda la realización periódica de análisis con marcadores tumorales (AFP, BhCG, LDH) hormonas (estrógenos, progesterona y testosterona), exploración física y TAC toracoabdominal.

La baja incidencia y el relativo desconocimiemto a largo plazo de este tipo de tumores, así como el hallazgo excepcional de características de neurosecreción en nuestro tumor y las escasas referencias en la literatura médica al respecto ${ }^{8}$, nos plantea la duda de si realmente este hecho pudiera ser clínicamente significativo o un hallazgo meramente casual.

B I B L I O G R A F Í A

1. Young RH, Koelliker DD, Scully RE. Sertoli cell tumors of the testis, not otherwise specified: A clinicopathologic analysis of 60 cases. Am J Surg Path. 1988;22:709.

2. Domínguez Molinero JF, Vergara Alcaide E, Fernández Rodríguez A, Nogueras Ocaña M, Martínez Torres JL, Zuluaga Gomez A.
Tumor testicular de células de Sertoli: variedades clínicas patológicas. A propósito de un caso. Act Urol Esp. 1997 519-23.

3. Chang B, Borer JG, Tan PE, Diamond D. Large-cell calcifying Sertoli cell tumor of the testis: Case report and review of the literature. Urology. 1998;52:520-2.

4. Giglio M, Medica M, Franco de Rose A, Germinale F, Ravetti JL, Carmigiani G. Testicular Sertoli cell tumours and relative subtypes. Analysis of clinical and prognostic features. Urol Int. 2003;70.

5. Werther M, Schmelz HU, Schwerer M. Sclerosing Sertoli cell tumor of the testis: A rare tumor. Case report and review of the literature on the subtypes of Sertoli-cell tumor. Urologe A. 2007;46:1551-6.

6. Henley JD, Young RH, Ulbright TM. Malignant Sertoli cell tumors of the testis: A study of 13 examples of a neoplasm frequently misinterpreted as seminoma. Am J Surg Pathol. 2002;26:541-50.

7. Azurmendi I, Llarena R, García-Olaverri J, Olano I, Cantón E, Pertusa C. Tumor de células de Sertoli maligno. Arch Esp Urol. 2008;61:834-7.

8. Kuroda N, Senzaki T, Yamasaki Y, Miyazaki E, Hayashi Y, Toi M. Sertoli cell tumor of the testis (not otherwise specified) with the expression of neuroendocrine markers and without the expression of inhibin-alpha. Pathol Int. 2004;54: 719-24.

9. Featherstone JM, Fernando HS, Theaker JM, et al. Sex cord stromal testicular tumors: A clinical series-uniformly stage I disease. J Urol. 2009;181:2090-6.

10. Valla JS. Testis sparing surgery for benign testicular tumors in children. J Urol. 2001;165:2280-3.

\section{J.D. Jiménez ${ }^{a}$,* J.L. Cebrián ${ }^{a}$, R. Guarch ${ }^{b}$ y A. Hualde ${ }^{a}$}

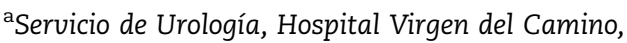
Pamplona, España

bervicio de Anatomía Patológica, Hospital Virgen

del Camino, Pamplona, España

*Autor para correspondencia.

Correo electrónico: jdjimenez@hotmail.es (J.D. Jiménez).

\section{Leiomioma bilateral y asincrónico de epidídimo: presentación de un caso}

\section{Bilateral and metachonous leiomyoma of the epidydimo: a case report}

\section{Sr. Director:}

Presentamos el caso clínico de un leiomioma de epidídimo bilateral de aparición asincrónica. Hemos realizado una revisión de los casos publicados en los últimos diez años analizando el diagnóstico, el tratamiento y el seguimiento.

Los leiomiomas de epidídimo son tumores benignos y poco habituales en la práctica clínica diaria. Representan el segundo grupo de tumores paratesticulares, siendo solo el $15 \%$ bilaterales.
Paciente varón de 60 años que acudió a la consulta externa derivado del médico de familia por elevación del antígeno prostático específico (PSA). El paciente refería antecedentes de orquiectomía por un tumor benigno de testículo, además de hipertensión arterial. Revisando el historial clínico, había sido intervenido hacía tres años por una masa paraescrotal derecha de $4 \mathrm{~cm}$ de diámetro máximo, practicándosele orquiectomía derecha más colocación de prótesis de silicona. El resultado del estudio anatomopatológico reveló una masa fusiforme de $4 \mathrm{~cm}$, localizada en la cola del epidídimo derecho, que fue 